\title{
SELF-REPORTED HEALTH STATUS PREDICTING RESILIENCE AND BURNOUT IN LONGITUDINAL STUDY
}

\author{
Iva Šolcová1, Vladimír Kebza², Miloslav Kodl ${ }^{3}$, Věra Kernová ${ }^{3}$ \\ ${ }^{1}$ Institute of Psychology, Academy of Sciences of the Czech Republic, Prague, Czech Republic \\ ${ }^{2}$ Department of Psychology, Czech University of Life Sciences, Prague, Czech Republic \\ ${ }^{3}$ National Institute of Public Health, Prague, Czech Republic
}

\begin{abstract}
SUMMARY
Objective: The study examined the links between health-related indicators, adult resilience, and burnout.

Method: The data were collected during two waves of the longitudinal study (in 2004-05, N=98, and 2011-12, $N=88$, respectively). Health behaviour, self-rated health (SRH), Sense of Coherence Scale (SOC), and Shirom-Melamed Burnout Measure (SMBM) were measured.

Results: The comprehensibility of SOC and physical fatigue of SMBM as measured in wave 2 were determined by SRH as measured in wave 1. In the cross-sectional part, the meaningfulness of SOC was related to SRH, and alcohol consumption in wave 1. The comprehensibility of SOC was related to SRH in wave 2.

Conclusion: SOC is well known to have effect on health. However, the results show that self-reported health had effect on the comprehensibility of SOC. Our data also support the finding that the effect of SRH on burnout is stronger than the effect of burnout on SRH.
\end{abstract}

Key words: sense of coherence, self-rated health, alcohol consumption, physical fatigue

Address for correspondence: I. Šolcová, Institute of Psychology, Academy of Sciences of the Czech Republic, Hybernská 8, 11000 Prague 1, Czech Republic. E-mail: solcova@praha.psu.cas.cz

https://doi.org/10.21101/cejph.a4840

\section{INTRODUCTION}

Resilience is defined as a universal capacity which allows a person, group, or community to prevent, minimize or overcome the damaging effects of adversity (1).

Historically, the research on the topic of resilience in adults has originated from studies that investigated the impacts of stressful events on people $(2,3)$. These studies were seeking characteristics and constellations of characteristics that identify people capable of better withstanding the impact of stressful events. Such characteristics or constellations of characteristics were assumed to buffer, transfer or negate the potential harmful impact of adverse events.

Currently, resilience is investigated in the framework of the studies of stress prevention and nurturing of positive strengths in individuals. The study of resilience has emerged from the shift of focus of psychological investigations from a problem-oriented approach to seeking positive strengths in individuals. There are several determinants of resilience including neurobiological, genetic, temperament, and environmental influences (4). To the best of the authors' knowledge, little work has focused on psychophysiological and biochemical processes that enhance the resilience of an individual. The prospective longitudinal investigations are mostly focused on protective factors such as sociability, intelligence, social competence, social ties, and support by family or significant others (5). The studies addressing biological deter- minants of resilience are mostly conducted with animal models (6), or focus on stress response and allostatic load (7).

This study is an exploratory study addressing the possible links between psychophysiological indicators and a measure of adult resilience, represented here by the Sense of Coherence. The second question addresses the possible links between psychophysiological indicators and measures of burnout syndrome as an outcome of chronic stress. As our study is based on longitudinal data, our next question concerns the relations between early factors (premature birth, birth weight, breast feeding, education of parents) and adult resilience.

Sense of coherence is conceptualized as an ability to use one's resources. Sense of coherence is the global orientation that the world is comprehensible, manageable, and meaningful (2). Comprehensibility is the degree to which individuals perceive the world as predictable, ordered, and explicable; manageability is the degree to which individuals believe that they have the personal and social resources to handle the demands; and meaningfulness is the belief that demands are challenges which are worthy of investment and commitment. As the sense of coherence has been developed to characterise persons that had been doing well despite adversity, the questionnaire Sense of Coherence is often used as a measure of adult resilience.

Burnout is viewed as a psychological strain representing a process of the depletion of personal coping resources in reaction 
to prolonged exposure to stress at work (8). The burnout syndrome emerges especially in certain professional groups as a result of a combination of factors including mainly chronic stress as well as a marked drop in motivation, interest in work and sense of satisfaction $(9,10)$. It has not only been an interesting and relatively serious psychological problem, but, as it impacts both the quality of life and health of people suffering from this syndrome, it also represents an important health issue (11).

The purpose of the study is to examine the links between health-related indicators and adult resilience, and to explore the relation between health-related indicators and burnout among participants of the longitudinal study.

\section{MATERIALS AND METHODS}

In the present study we used data from the project "Longitudinal monitoring of growth and mental development of a normal child in a group of individuals from the capital city of Prague since their birth" that was carried out by the Institute of Hygiene and Epidemiology (later the National Institute of Public Health) in Prague between 1956 and 1980. The rebirth of the project came with the transition process in the Czech Republic in 1994. As there was considerable time gap between rebirth in 1994 and the last survey carried out in 1980 , only a part of the original sample was found. In 1994, 112 persons from 287 new-borns recruited at the beginning of the study participated.

The next survey took place in 2004-2005 (in participants aged 45 to 49 years), followed by a survey conducted in the years 2011-2012 (in participants aged 52 to 56 years), and the study continues as a study of life span development.

In the wave conducted in 2004-2005, 98 respondents participated ( 53 women, mean age $=45.321, \mathrm{SD}=2.953$, and 45 men, mean age $=45.400, \mathrm{SD}=1.935)$. In the wave conducted in 2011-2012, 88 respondents participated (49 women, mean age $=53.041, \mathrm{SD}=2.937,37$ men, mean age $=51.676, \mathrm{SD}=2.249$ ). The sample thus represented $34.1 \%$ and $29.6 \%$ of the original sample, respectively.

Participants were examined by psychological methods and by somatic and physiological measures (both waves) and selected biochemical measures (wave 2, 2011-2012). They were also administered a simple health questionnaire including issues focused on selected behavioural aspects of health.

The survey conducted in 2004-2005 (wave 1) included the measure of Sense of Coherence, somatic and physiological measures, health questionnaire and measures devoted to behavioural aspects of health. The survey conducted in 2011-2012 (wave 2) included the measure of Sense of Coherence, measure of burnout, somatic and physiological measures, selected biochemical measures, and health questionnaire focused on subjective and objective health, and selected behavioural aspects of health.

The Sense of Coherence Scale (SOC, 2) consists of 29 items, which measure three components of the construct: comprehensibility (11 items, e.g. "Do you have very mixed-up feelings and ideas?"), manageability (10 items, e.g. "Do you have the feeling that you're being treated unfairly?"), and meaningfulness (8 items, e.g. "How often do you have the feeling that there's little meaning in the things you do in your daily life?"). Respondents rated items on a seven-point Likert-type scale, yielding an overall score between 0 and 203. The higher the score, the higher is one's sense of coherence and its components. The SOC was administered in both waves.

The measure has shown respectable internal consistency and reliability in literature: according to Eriksson and Lindström (12) Cronbach's alpha ranged from 0.70 to 0.92 .

Cronbach's alpha of our sample is 0.81 for manageability scale, 0.86 for meaningfulness scale, 0.83 for comprehensibility scale, and 0.93 for the whole questionnaire in the survey conducted in wave 2 .

The Shirom-Melamed Burnout Measure (SMBM, 8) consists of three subscales: physical fatigue (six items, e.g. "I feel tired; I feel physically fatigued"), emotional exhaustion (three items, e.g. "I feel I am not capable of investing emotionally in co-workers and customers"), and cognitive weariness (six items, e.g. "I am too tired to think clearly; I feel that I think slowly"). Respondents are asked to rate the frequency of each feeling during their work. Items are scored on a 7-point frequency scale, ranging from 1 (almost never) to 7 (almost always). The high scores indicate high level of subscales. The reliability coefficient (Cronbach's alpha) of the Czech version is 0.92 for physical fatigue, 0.93 for cognitive weariness, and 0.76 for emotional exhaustion in the present study. The questionnaire was administered in wave 2 .

Physical examinations comprised BMI, WHR, and systolic and diastolic blood pressure. The values above norm were scored 1 . Normal values were scored 0 .

In wave 2, selected biochemical data (total cholesterol, triglycerides, glycaemia) were collected. The values above norm were scored 1 . Normal values were scored 0 .

\section{Health Questionnaire}

Regular usage of medicines. Positive responses were scored 1. Smoking (Do you smoke? If yes, how many cigarettes per day? If yes, how many years have you smoked? If not, have you ever smoked?) All respondents currently smoking were considered smokers (scored 1).

Alcohol (Do you drink alcohol? If yes, how often? If yes, how many units per week?) All respondents drinking regularly above 2 units per week obtained score 1 . Others were scored 0.

Physical activity (How many kilometres per week do you cover by your own power: walking, jogging, and cycling). No physical activity was scored as 1 .

Self-reported health (SRH) (In general, would you say your health in the last 12 months has been ... (circle one number)?) The scale from 1 (excellent) to 5 (poor) was provided to respondents.

Chronic health problems (Do you suffer from long term (more than 6 months) problems concerning your heart and circulatory system, breathing, nervous system, digestive system, motion, renal and urological system, liver and bladder, other problems?) Negative responses to all issues means score 0 , one positive response means score 1.

Objective health was derived from the question concerning diagnoses stated to the respondent by a physician (Has your physician diagnosed you with any of the diseases listed below?) The respondent had at his/her disposal a list of possible problems: myocardial infarction, angina pectoris, IHD, stroke, high blood pressure, diabetes, cancer, gastric ulcer, bladder disease, kidney stone, asthma, illness of vertebra and/or joints. There was also the possibility to add a problem that was not on the list. Nega- 
tive responses to all issues means score 0 , one positive response means score 1.

Health in the family was derived from the question concerning diseases (the same list as for objective health index) diagnosed to parents, siblings, and children. Negative responses to all issues means score 0 , one positive response means score 1 .

\section{Statistical Analyses}

Multiple linear regression analyses were employed to process the data. Inspection of the regression diagnostics revealed no multicollinearity among the independent variables: we used
Variance Inflation Factors (VIF) and no value exceeded 4. Due to explorative character of the study we used the Enter method. The data were processed with the use of Intercooled Stata 7.0 software. In the analyses, the dependent variables were the total score of SOC and its components, and the total score of SMBM and its components. Only significant results of the regression analyses were reported in the study, however, all results can be obtained from authors.

Throughout the paper, we present p-values of regression models that are considered significant at $\alpha=0.05$ and $p$-values of predictors that are considered significant at the $\alpha=0.005$ level to capture most robust predictors.

Table 1. Predictors of Sense of Coherence comprehensibility in wave 2

\begin{tabular}{|c|c|c|c|c|c|c|c|}
\hline & & \multirow{2}{*}{ Coef. B } & \multirow{2}{*}{ SE } & \multirow{2}{*}{$t$} & \multirow{2}{*}{$p$-value } & \multicolumn{2}{|c|}{$95 \% \mathrm{Cl}$} \\
\hline & & & & & & Lower & Upper \\
\hline \multirow{12}{*}{ Wave 1} & BMI & -0.396 & 2.319 & -0.17 & 0.865 & -5.029 & 4.236 \\
\hline & BPS & 6.675 & 4.601 & 1.45 & 0.152 & -2.514 & 15.86 \\
\hline & BPD & 6.120 & 5.140 & 1.19 & 0.238 & -4.146 & 16.38 \\
\hline & SRH & -18.1 & -3.85 & 4.70 & $<0.001$ & -27.51 & -8.720 \\
\hline & Chronic problems & 6.168 & 2.675 & 2.31 & 0.024 & 0.825 & 11.51 \\
\hline & Objective health & 0.029 & 2.413 & 0.01 & 0.990 & -4.790 & 4.850 \\
\hline & CVD & -4.146 & 6.022 & -0.69 & 0.494 & -16.17 & 7.880 \\
\hline & Overweight & -0.560 & 5.721 & -0.10 & 0.922 & -11.98 & 10.86 \\
\hline & Asthma & 1.747 & 5.568 & 0.31 & 0.755 & -9.372 & 12.86 \\
\hline & Smoking & -2.693 & 2.386 & -1.13 & 0.263 & -7.459 & 2.073 \\
\hline & Alcohol & -2.103 & 2.343 & -0.90 & 0.373 & -6.783 & 2.576 \\
\hline & Cons & 49.11 & 3.008 & 16.33 & $<0.001$ & 43.10 & 55.12 \\
\hline
\end{tabular}

$\mathrm{N}=77, \mathrm{~F}(11,65)=2.26$, Prob $>\mathrm{F} \mathrm{p}=0.021, \mathrm{R}^{2}=0.276$, Adj $\mathrm{R}^{2}=0.154$, Root MSE $=9.069$

$\mathrm{BMI}=$ body mass index; $\mathrm{BPS}=$ systolic blood pressure; $\mathrm{BPD}=$ diastolic blood pressure; $\mathrm{SRH}=$ self-rated health; $\mathrm{CVD}=$ cardiovascular disease; chronic problems = reported chronic problems lasting more than 6 months; objective health = diseases diagnosed by physician

Table 2. Regression analysis on Sense of Coherence meaningfulness in wave 1

\begin{tabular}{|c|c|c|c|c|c|c|}
\hline & \multirow{2}{*}{ Coef. B } & \multirow{2}{*}{ SE } & \multirow{2}{*}{$\mathrm{t}$} & \multirow{2}{*}{$p$-value } & \multicolumn{2}{|c|}{$95 \% \mathrm{Cl}$} \\
\hline & & & & & Lower & Upper \\
\hline BMI & 0.3169 & 1.629 & 0.19 & 0.846 & -2.935 & 3.569 \\
\hline BPS & -3.258 & 3.247 & -1.00 & 0.319 & -9.740 & 3.224 \\
\hline BPD & 0.136 & 3.468 & 0.04 & 0.969 & -6.787 & 7.061 \\
\hline $\mathrm{SRH}$ & -9.815 & 3.330 & -2.95 & 0.004 & -16.46 & -3.166 \\
\hline Chronic problems & 4.092 & 1.884 & 2.17 & 0.034 & 0.330 & 7.856 \\
\hline Objective health & -1.808 & 1.731 & -1.04 & 0.300 & 5.265 & -1.648 \\
\hline CVD & 4.199 & 4.139 & 1.01 & 0.314 & -4.065 & 12.46 \\
\hline Overweight & 1.278 & 4.072 & 0.31 & 0.755 & -6.853 & 9.409 \\
\hline Asthma & 1.212 & 3.946 & 0.31 & 0.760 & -6.666 & 9.091 \\
\hline Smoking & 1.960 & 1.714 & 1.14 & 0.257 & -1.462 & 5.383 \\
\hline Alcohol & -5.040 & 1.625 & -3.10 & 0.003 & -8.284 & -1.795 \\
\hline Cons & 42.375 & 2.120 & 19.98 & $<0.001$ & 38.141 & 46.61 \\
\hline
\end{tabular}

$\mathrm{N}=78, \mathrm{~F}(11,66)=2.40$, Prob $>\mathrm{F} \mathrm{p}=0.014, \mathrm{R}^{2}=0.285$, Adj $\mathrm{R}^{2}=0.166$, Root MSE $=6.422$

$\mathrm{BMI}=$ body mass index; $\mathrm{BPS}=$ systolic blood pressure; $\mathrm{BPD}=$ diastolic blood pressure; $\mathrm{SRH}=$ self-rated health; $\mathrm{CVD}=$ cardiovascular disease; chronic problems = reported chronic problems lasting more than 6 months; objective health = diseases diagnosed by physician 


\section{RESULTS}

\section{Predictors of Resilience}

The comprehensibility of SOC (Table 1) as measured in wave 2 was determined by self-reported health as measured in wave 1 (negative relation, i.e. the better SRH, the higher comprehensibility)
Variables related to resilience in cross-sectional study

Wave 1, 46-49 years of age

The meaningfulness of SOC (Table 2) was related to self-rated health (negative relation), and alcohol consumption (negative relation).

Wave 2, 52-56 years of age*

The comprehensibility of SOC (Table 3 ) was related to self-rated health (negative relation, the better SRH, the higher comprehensibility)

Table 3. Regression analysis on Sense of Coherence comprehensibility in wave 2

\begin{tabular}{|c|c|c|c|c|c|c|}
\hline & \multirow{2}{*}{ Coef. B } & \multirow{2}{*}{ SE } & \multirow{2}{*}{$\mathrm{t}$} & \multirow{2}{*}{$\mathrm{p}$-value } & \multicolumn{2}{|c|}{$95 \% \mathrm{Cl}$} \\
\hline & & & & & Lower & Upper \\
\hline BMI & 2.945 & -2.524 & -1.17 & 0.247 & -7.978 & 2.087 \\
\hline BPS & 5.127 & 2.535 & 2.02 & 0.047 & 0.073 & 10.18 \\
\hline BPD & -0.499 & 2.590 & -0.19 & 0.848 & -5.662 & 4.664 \\
\hline SRH & -11.16 & 3.840 & -2.91 & 0.005 & -18.82 & -3.507 \\
\hline Chronic problems & 0.735 & 2.179 & 0.34 & 0.737 & -3.609 & 5.081 \\
\hline Objective health & -1.501 & 2.774 & -0.54 & 0.590 & -7.032 & 4.030 \\
\hline CVD & 7.170 & 2.903 & 2.47 & 0.016 & 1.381 & 12.95 \\
\hline Overweight & 9.565 & 6.135 & 1.56 & 0.123 & -2.664 & 21.79 \\
\hline Asthma & 4.013 & 4.058 & 0.99 & 0.326 & -4.076 & 12.10 \\
\hline Smoking & -0.381 & 2.339 & -0.16 & 0.871 & -5.045 & 4.282 \\
\hline Alcohol & 2.926 & 2.745 & 1.07 & 0.290 & -2.546 & 8.398 \\
\hline Cons & 47.11 & 3.418 & 13.78 & $<0.001$ & 40.30 & 53.92 \\
\hline
\end{tabular}

Number of obs $=85, F(12,72)=2.40$, Prob $>F p=0.011, R^{2}=0.286$, Adj $R^{2}=0.167$, Root MSE $=9.133$

$\mathrm{BMI}=$ body mass index; BPS = systolic blood pressure; $\mathrm{BPD}=$ diastolic blood pressure; $\mathrm{SRH}=$ self-rated health; $\mathrm{CVD}=$ cardiovascular disease; chronic problems = reported chronic problems lasting more than 6 months; objective health = diseases diagnosed by physician

Table 4. Predictors of physical fatigue of Shirom-Melamed Burnout Measure in wave 2

\begin{tabular}{|c|c|c|c|c|c|c|c|}
\hline & \multirow{2}{*}{ Physical fatigue } & \multirow{2}{*}{ Coef. B } & \multirow{2}{*}{ SE } & \multirow{2}{*}{$t$} & \multirow{2}{*}{$p$-value } & \multicolumn{2}{|c|}{$95 \% \mathrm{Cl}$} \\
\hline & & & & & & Lower & Upper \\
\hline \multirow{12}{*}{ Wave 1} & BMI & 0.564 & 1.683 & 0.34 & 0.739 & -2.799 & 3.927 \\
\hline & BPS & -0.653 & 3.321 & -0.20 & 0.845 & -7.289 & 5.983 \\
\hline & BPD & 5.974 & 3.714 & 1.61 & 0.113 & -1.446 & 13.39 \\
\hline & SRH & 14.23 & 3.397 & 4.19 & $<0.001$ & 7.452 & 21.02 \\
\hline & Chronic problems & 1.045 & 1.931 & 0.54 & 0.590 & -2.814 & 4.904 \\
\hline & Objective health & 2.154 & 1.775 & 1.21 & 0.230 & -1.393 & 5.702 \\
\hline & CVD & -6.082 & 4.352 & -1.40 & 0.167 & -14.77 & 2.612 \\
\hline & Overweight & -1.029 & 4.158 & -0.25 & 0.805 & 9.337 & -7.278 \\
\hline & Asthma & -1.606 & 4.023 & -0.40 & 0.691 & -9.645 & 6.431 \\
\hline & Smoking & 1.409 & 1.765 & 0.80 & 0.428 & -2.116 & 4.936 \\
\hline & Alcohol & 2.763 & 1.700 & 1.63 & 0.109 & -.6332 & 6.160 \\
\hline & Cons & 14.18 & 2.171 & 6.53 & $<0.001$ & 9.847 & 18.52 \\
\hline
\end{tabular}

$N=76, F(11,64)=2.62$, Prob $>F p=0.008, R^{2}=0.310$, Adj $R^{2}=0.191$, Root MSE $=6.547$

$\mathrm{BMI}=$ body mass index; $\mathrm{BPS}=$ systolic blood pressure; $\mathrm{BPD}=$ diastolic blood pressure; $\mathrm{SRH}=$ self-rated health; $\mathrm{CVD}=$ cardiovascular disease; chronic problems = reported chronic problems lasting more than 6 months; objective health = diseases diagnosed by physician;

*In wave 2 we added some biochemical indicators; however none of them appeared to become a robust determinant of dependent variables. For that reason we performed linear regression analyses in which we entered the same indicators as in wave 1 to enable comparison of both waves. 


\section{Predictors of Burnout}

Physical fatigue of the SMBM as measured in wave 2 was determined by the level of self-reported health as measured in wave 1 (Table 4).

\section{DISCUSSION}

\section{Predictors of SOC}

The determination of the comprehensibility of SOC by selfrated health is very interesting. SRH is well known as a valid and robust indicator with high predictive power concerning morbidity and mortality (13-16). It appears that an individual's view of his/her health is irreplaceable, as it likely reflects the aspects of health status that are not approachable by other measures, e.g. incipient phases of disease, the seriousness of the disease, psychological and psychophysiological resources and reserves, social and mental aspects of the disease, etc. Subjects' responses to self-rated health item maintained strong predictive power even after adjustment for functional status, depression, and co-morbidity (17).

It is well known that SOC is a health-protective (salutoprotective) characteristic (18). SOC has been the answer to the question of why some people stay well under the same conditions that make other people sick. However, from our results it follows causality of opposite direction (i.e. self-reported health predicted the level of comprehensibility).

\section{Relations of SOC in Cross-sectional Study}

The relation of alcohol consumption with SOC components in participants aged 45 years is interesting. As this part of the results is cross-sectional, it is not possible to determine the causality. In the scientific literature, we found studies supporting Antonovsky's original concept of increased alcohol consumption as a result of failed coping strategies $(19,20)$. However, the possibility that alcohol consumption might blunt the components of SOC cannot be excluded. Moreover, the above mentioned studies were conducted with heavy drinkers, whereas in our study we encountered moderate consumers of alcohol.

The meaningfulness of $\mathrm{SOC}$ was related to $\mathrm{SRH}$ in wave 1. The causality is not clear in case of cross-sectional results; however, our hypothesis for the future is a possible impact of SRH on the meaningfulness of SOC.

The concurrent relations in wave 2 showed that the relation of any component of SOC to alcohol consumption is not significant. T-test showed that alcohol consumption decreased significantly in wave $2(p=0.006)$. In the second wave, the comprehensibility of SOC is related to self-rated health, and the causality cannot be determined; however, as SRH predicted the comprehensibility 7 years later, the same causality can be hypothesized.

\section{Predictors of Burnout}

Self-rated health in 45 -year olds determined physical fatigue of SMBM seven years later: the poorer the health, the higher the burnout level. It is well known that persons who suffer from burnout may suffer from headaches, dizziness, sleeping problems, stomach pain, and back pain - to name only moderate health problems (21-23).

As early as the 1980s, professional literature all over the world began to reflect possible associations between burnout and levels of cardiovascular disease (CVD) risk factors (24). This and other findings (25-29) indicate a very likely relationship between burnout syndrome and acute myocardial infarction, ischaemic heart disease, cerebral apoplexy, and sudden cardiac death. The majority of cases lead to the assumption that the burnout syndrome is more likely to precede CVD rather than emerge as a result.

The opposite relation, i.e. poor self-rated health as a determinant of later burnout, has been studied less frequently. According to Shirom (30), good health as indexed by SRH should be negatively linked to burnout because it represents a pivotal coping resource and any changes in it are likely to have an impact on one's level of burnout. Vinokur et al. (31) were able to demonstrate this in a longitudinal study: according to their findings, perceived health as measured in 2001 predicted a decrease in burnout as measured in 2004. Their data provided support for the coexisting of both types of effects, i.e. burnout predicted decrease in perceived health. According to their study, the effect of selfrated health on burnout is stronger than the effect of burnout on self-rated health. Our data thus support the finding of Vinokur et al. (2009) in a far longer time interval between predicting variable and dependent variable. Concurrent relation of SRH and physical fatigue is in agreement with relations of both variables in longitudinal view.

\section{Study Limitations}

Of course, there are some limitations to our study. The sample is not big enough according to some standards. On the other side, the sample homogeneity in the years of survey, age and birth cohort might represent an advantage. Some findings might be sample specific. It is necessary to examine the generalizability of our results.

\section{CONCLUSIONS}

The longitudinal design of the study enabled us to show predictive effects of SRH on resilience (SOC) and burnout. The crosssectional study revealed the negative relation between alcohol consumption and resilience (SOC). Our task for the future is to seek the mechanisms explaining the described relations.

\section{Acknowledgements}

This work was supported by the Czech Science Foundation under grant no. GA15-22474S, "Predictors of generativity in middle adulthood: A longitudinal study" and by RVO: 68081740 .

\section{REFERENCES}

1. Grotberg EH. The international resilience project: findings from the research and the effectiveness of interventions. In: Bain B, Janzen H, Paterson J, Stewin L, Yu A, editors. Psychology and education in the 21st century: Proceedings of the 54th annual convention of the International Council of Psychologists; 1996 July 24-28; Banff, Canada. Edmonton (AB): ICPress; 1997. p. 153-8. 
2. Antonovsky A. Unravelling the mystery of health. How people manage stress and stay well. San Francisco: Jossey-Bass; 1987.

3. Kobasa SC. Commitment and coping in stress resistance among lawyers. J Pers Soc Psychol. 1982 Apr;42(4):707-17.

4. Connor KM, Zhang W. Recent advances in the understanding and treatment of anxiety disorders. Resilience: determinants, measurement, and treatment responsiveness. CNS Spectr. 2006 Oct;11(10 Suppl 12):5-12.

5. Werner EE, Smith RS. Overcoming the odds: high-risk children from birth to adulthood. Ithaca (NY): Cornell University Press; 1992.

6. Franklin TB, Saab BJ, Mansuy IM. Neural mechanisms of stress, resilience and vulnerability. Neuron. 2012 Sep 6;75(5):747-61

7. Karatsoreos IN, McEwen BS. Psychobiological allostasis: resistance, resilience and vulnerability. Trends Cogn Sci. 2011 Dec;15(12):576-84.

8. Shirom A, Melamed S. A comparison of the construct validity of two burnout measures among two groups of professionals. Int J Stress Manag. 2006;13(2):176-200.

9. Kebza V, Šolcová I. Burnout syndrome: theoretical sources, diagnostic and treatment possibilities. Cesk Psychol. 1998;42(5):429-48. (In Czech.)

10. Kebza V, Šlcová I. Burnout syndrome - review of contemporary state of knowledge and perspectives for the future. Cesk Psychol. 2008;52(4):35165. (In Czech.)

11. Kebza V, Šolcová I. Burnout syndrome, selected psychological variables, and risk factors of cardiovascular diseases. In: Winston TN, editor. Handbook on burnout and sleep deprivation: risk factors, management strategies and impact on performance and behavior New York: Nova Science Publishers; 2015. p. 129-40.

12. Eriksson M, Lindström B. Validity of Antonovsky's sense of coherence scale: a systematic review. J Epidemiol Community Health. 2005 Jun;59(6):460-6.

13. Benyamini Y, Leventhal EA, Leventhal H. Self-assessments of health What do people know that predicts their mortality? Res Aging. 1999 May;21(3):477-500.

14. Idler EL, Benyamini Y. Self-rated health and mortality: a review of twentyseven community studies. J Health Soc Behav. 1997 Mar;38(1):21-37.

15. Idler EL, Russell LB, Davis D. Survival, functional limitations, and selfrated health in the NHANES I Epidemiologic Follow-up Study, 1992 First National Health and Nutrition Examination Survey. Am J Epidemiol. 2000 Nov 1;152(9):874-83.

16. McGee DL, Liao Y, Cao G, Cooper RS. Self-reported health status and mortality in multi-ethnic US cohort. Am J Epidemiol. 1999 Jan 1;149(1):41-6.

17. DeSalvo KB, Bloser N, Reynolds K, He J, Muntner P. Mortality prediction with a single general self-rated health question: a meta-analysis. J Gen Intern Med. 2006 Mar;21(3):267-75.

18. Volanen SA. Sense of coherence: determinants and consequences [dissertation]. Helsinki: University of Helsinki; 2011.
19. Midanik LT, Soghikian K, Ransom LJ, Polen MR. Alcohol problems and sense of coherence among older adults. Soc Sci Med. 1992 Jan;34(1):43-8.

20. Neuner B, Miller P, Maulhardt A, Weiss-Gerlach E, Neumann T, Lau A, et al. Hazardous alcohol consumption and sense of coherence in emergency department patients with minor trauma. Drug Alcohol Depend. 2006 Apr 28;82(2):143-50

21. De Vente W, Olff M, Van Amsterdam JG, Kamphuis JH, Emmelkamp PMG. Physiological differences between burnout patients and healthy controls: blood pressure, heart rate, and cortisol responses. Occup Environ Med. 2003 Jun;60 Suppl 1:i54-61.

22. Mommersteeg PM. The psychophysiology of burnout. Utrecht: Utrecht University; 2006.

23. Söderström M, Ekstedt M, Åkerstedt T, Nilsson J, Axelsson J. Sleep and sleepiness in young individuals with high burnout scores. Sleep. 2004 Nov 1;27(7):1369-77.

24. Belcastro PA. Burnout and its relationship to teachers' somatic complaints and illnesses. Psychol Rep. 1982 Jun;50(3 Pt 2):1045-6.

25. Appels A, Otten F. Exhaustion as a precursor of cardiac death. Br J Clin Psychol. 1992 Sep;31( Pt 3):351-6.

26. Hallman T, Thomsson H, Burell G, Lisspers J, Setterlind S. Stress, burnout and coping: differences between women with coronary heart disease and healthy matched women. J Health Psychol. 2003 Jul;8(4):433-45.

27. Melamed S, Kushnir T, Shirom A. Burnout and risk factors for cardiovascular disease. Behav Med. 1992 Summer;18(2):53-60.

28. Melamed S, Shirom A, Toker S, Berliner S, Shapira I. Burnout and risk of cardiovascular disease: evidence, possible causal paths, and promising research directions. Psychol Bull. 2006 May;132(3):327-53.

29. Shirom A. Burnout and physical health. Evidence, possible causal paths, and promising research directions. State-of-the art lecture. In: Proceedings of the 10th European Congress of Psychology; 2007 July 3-6; Prague, Czech Republic. Prague: Union of Psychologists Association of the Czech Republic: 2007. p. 161.

30. Shirom A. Employee burnout and health: current knowledge and future research paths. In: Houdmont J, Leka S, editors. Contemporary occupational health psychology: global perspectives on research and practice. Volume 1. Oxford: Wiley-Blackwell; 2010. p. 59-76.

31. Vinokur AD, Pierce PF, Lewandowski-Romps L. Disentangling the relationships between job burnout and perceived health in a military sample. Stress Health. 2009 Oct;25(4):355-63. 